\title{
Optimisation of cardiac resynchronisation therapy during exercise
}

\author{
A. Ghani • A. R. Ramdat Misier • A. Elvan • \\ P. P. H. M. Delnoy
}

Published online: 7 August 2013

(C) The Author(s) 2013. This article is published with open access at Springerlink.com

The benefits of cardiac resynchronisation therapy (CRT) in selected cohorts with systolic dysfunction and congestive heart failure are well established [1-3]. CRT reduces heart failure hospitalisations, decreases mortality, and improves the quality of life and cardiac function, described as left ventricular (LV) reverse remodelling. CRT improves inter-, intra- and atrio-ventricular dyssynchrony. It is important to stress that there is only a moderate correlation between clinical and echocardiographic response; i.e. patients with improvement in their clinical status might not always show significant reverse remodelling. Nevertheless, the number of patients who do not respond to this therapy remain as high as $30 \%$ to $40 \%$. The reasons for not responding to CRT are probably complex and multifactorial. Patient selection, accurate assessment of dyssynchrony, LV lead placement and optimal position and device programming are of importance. This necessitates a comprehensive evaluation of baseline and postimplant clinical, electrocardiographic and echocardiographic data. Moreover, LV lead position optimisation and device interrogation are useful for optimising CRT and should be considered to maximise the therapeutic response to CRT. It is recommended to perform AV-delay optimisation in all patients, guided either by the device or by echocardiography. However, the role of AV and VV optimisation regarding longterm outcome remain debatable. The SMART AV trial [4] showed that patients with normal AV delay did not derive benefit from echo-guided or device-guided AV optimisation compared with the empiric settings. However, patients with prolonged $\mathrm{AV}$ conduction were not included in this prospective, randomised trial. Moreover, in the Freedom trial [5] the

A. Ghani $(\bowtie) \cdot$ A. R. Ramdat Misier • A. Elvan • P. P. H. M. Delnoy Department of Cardiology, Isala Klinieken, Groot Wezenland 20, 8011 JW Zwolle, the Netherlands

e-mail: v.r.c.derks@isala.nl authors concluded that routine AV and VV optimisation, by echo or the QuickOpt algorithm in unselected CRT recipients, did not appear to contribute significantly to further improving responsiveness to CRT. A variety of techniques, including echocardiography-guided methods, have been described to determine the optimal AV and VV delays. Many of these techniques have poor reproducibility and are timeconsuming [6,7]. None of these techniques have been shown to be superior and long-term benefits are lacking. Most device-based algorithms allow a rapid, simplified approach to CRT optimisation. However, their clinical value has also been called into question. Only the CLEAR study $[8,9]$ results suggest the clinical value of frequent CRT optimisation by SonR $\mathrm{R}^{\mathrm{TM}}$ algorithm or echocardiography in severe chronic heart failure patients in the long-term.

Recently a new non-invasive finger plethysmographic (Nexfin) method has been used for AV optimisation [10]. The Nexfin device, which allows measurement of beat-tobeat stroke volume (SV), was validated against echocardiography and the Riva-Rocci/Korotkoff method [11, 12] and AV optimisation by this device led to an almost $7 \%$ increase in SV [10].

In this issue of the Journal, Molenaar et al.[13] present their data on optimisation of CRT in clinical practice during exercise using the Nexfin device. They found a heterogeneous optimal AV delay in their small-sized study population. Currently, optimisation of pacing settings is mainly performed during resting conditions [14].

A few questions can be asked. The first question is whether the optimal AV delay changes during exercise in heart failure patients? Bogaard et al. [14] reviewed the literature and found seven small-sized studies which addressed this issue. The reported results were not consistent: a shortening, lengthening or no change in optimal AV delay during exercise was observed. Based on the physiological properties of the AV node 
in healthy subjects, these heterogeneous responses to exercise were unexpected [14]. The optimal physiological response to exercise in heart failure patients is probably different compared with healthy subjects. Thus, the findings of Molenaar et al. on the true heterogeneous effect of AV optimisation in heart failure patients are in line with previous reports [14].

The second question is whether the programming of a rateadaptive AV delay has a significant influence on outcome. In the same review by Bogaard et al. [14] it was concluded that in all the studies only acute haemodynamic outcomes were assessed. Molenaar et al. showed an increase of $10 \%$ in stroke volume. This is again an acute haemodynamic measurement. An interesting and relevant question is whether this adaptive AV delay, which is a time-consuming method, has an influence on functional NYHA class and exercise capacity in heart failure patients. Therefore, the long-term follow-up results of their study will be very interesting.

Finally, Molenaar et al. used a non-invasive method provided by the Nexfin device, which is relatively new and is not yet well validated for this purpose. Other methods such as echocardiography, including transmitral flow and LV outflow tract velocity (LVOT-VTI) measurements, have been used much more in clinical practice $[6,7]$. Nevertheless, these methods are time-consuming and are moderately reproducible. Device-based algorithms such as QuickOpt and Smart AV did not show any benefit compared with nominal settings and were not tested during exercise. At the moment, programming a sensed AV delay of 100-120 ms still seems the best practice in the majority of patients until more data on clinical outcome become available $[4,10,14]$. Currently, two multicentre and randomised trials (Bio-Detect HF and Respond CRT) are investigating the benefits of optimising AV and VV delay on clinical outcome by device-based automated algorithm.

In summary, the $10 \%$ increase in stroke volume due to AVdelay optimisation by the Nexfin device during exercise, which Molenaar et al. have showed, is a very interesting and encouraging result. However, the current methods of optimising rateadaptive AV delay, including the Nexfin method, need to be tested in a larger number of patients with a longer follow-up before definite conclusions can be made.

\section{Funding None.}

Conflict of interests None declared.

Open Access This article is distributed under the terms of the Creative Commons Attribution License which permits any use, distribution, and reproduction in any medium, provided the original author(s) and the source are credited.

\section{References}

1. Vardas PE, Auricchio A, Blanc JJ, et al. Guidelines for cardiac pacing and cardiac resynchronization therapy: The Task Force for Cardiac Pacing and Cardiac Resynchronization Therapy of the European Society of Cardiology. Developed in collaboration with the European Heart Rhythm Association. Eur Heart J. 2007;28:2256-95.

2. Tang AS, Wells GA, Talajic M, et al. Resynchronizationdefibrillation for ambulatory heart failure trial investigators. Cardiac-resynchronization therapy for mild-to-moderate heart failure. N Engl J Med. 2010;363:2385-95.

3. Moss AJ, Hall WJ, Cannom DS, et al. MADIT-CRT Trial Investigators. Cardiac-resynchronization therapy for the prevention of heartfailure events. N Engl J Med. 2009;361:1329-38.

4. Ellenbogen KA, Gold MR, Meyer TE, et al. Primary results from the SmartDelay determined AV optimization: a comparison to other AV delay methods used in cardiac resynchronization therapy (SMART$\mathrm{AV})$ trial: a randomized trial comparing empirical, echocardiographyguided, and algorithmic atrioventricular delay programming in cardiac resynchronization therapy. Circulation. 2010;122:2660-8.

5. Abraham WT, Gras D, Yu CM, et al. FREEDOM Steering Committee. Rationale and design of a randomized clinical trial to assess the safety and efficacy of frequent optimization of cardiac resynchronization therapy: the Frequent Optimization Study Using the QuickOpt Method (FREEDOM) trial. Am Heart J. 2010;159:944-8.

6. Auricchio A, Ding J, Spinelli JC, et al. Cardiac resynchronization therapy restores optimal atrioventricular mechanical timing in heart failure patients with ventricular conduction delay. J Am Coll Cardiol. 2002;39:1163-9.

7. Gold MR, Niazi I, Giudici M, et al. A prospective comparison of AV delay programming methods for hemodynamic optimization during cardiac resynchronization therapy. J Cardiovasc Electrophysiol. 2007; $18: 490-6$

8. Delnoy PP, Ritter P, Naegele H, et al. Association between frequent cardiac resynchronization therapy optimization and long-term clinical response: a post hoc analysis of the Clinical Evaluation on Advanced Resynchronization (CLEAR) pilot study. Europace. 2013 Mar 14. [Epub ahead of print]

9. Ritter P, Delnoy PP, Padeletti L, et al. randomized pilot study of optimization of cardiac resynchronization therapy in sinus rhythm patients using a peak endocardial acceleration sensor vs. standard methods. Europace. 2012;14:1324-33.

10. Van Geldorp IE, Delhaas T, Hermans B, et al. Comparison of a noninvasive arterial pulse contour technique and echo Doppler aorta velocity-time integral on stroke volume changes in optimization of cardiac resynchronization therapy. Europace. 2011;13:87-95.

11. Chen G, Meng L, Alexander B, et al. Comparison of noninvasive cardiac output measurements using the Nexfin monitoring device and the esophageal Doppler. J Clin Anesth. 2012;24:275-83.

12. Eeftinck Schattenkerk DW, van Lieshout JJ, van den Meiracker AH, et al. Nexfin noninvasive continuous blood pressure validated against Riva-Rocci/Korotkoff. Am J Hypertens. 2009;22:378-83.

13. Molenaar MM, Oude Velthuis B, Scholten MF, et al. Optimization of cardiac resynchronization therapy in clinical practice during exercise. Neth Heart J (Epub ahead of publication) doi:10.1007/s12471-0130438-3.

14. Bogaard MD, Kirkels JH, Hauer RN, et al. Should we optimize cardiac resynchronization therapy during exercise? J Cardiovasc Electrophysiol. 2010;21:1307-16. 